Acta Crystallographica Section C

Crystal Structure

Communications

ISSN 0108-2701

\section{The crystal packing of 4,7-dichloro- and 4,7-dibromobenzo[c]furazan 1-oxide}

\author{
Doyle Britton, ${ }^{\text {a* }}$ Frank B. Mallory ${ }^{\mathrm{b}}$ and Clelia W. Mallory ${ }^{\mathrm{c}}$

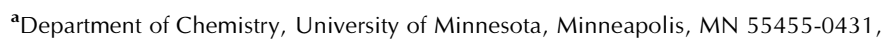 \\ USA, 'bepartment of Chemistry, Bryn Mawr College, Bryn Mawr, PA 19010-2899, \\ USA, and ${ }^{\mathrm{C}}$ Department of Chemistry, University of Pennsylvania, Philadelphia, \\ PA 19104-6323, USA \\ Correspondence e-mail: britton@chem.umn.edu
}

Received 15 January 2002

Accepted 25 February 2002

Online 21 March 2002

The molecular structures of 4,7-dichlorobenzo[c]furazan 1-oxide, $\mathrm{C}_{6} \mathrm{H}_{2} \mathrm{Cl}_{2} \mathrm{~N}_{2} \mathrm{O}_{2}$, (I), and 4,7-dibromobenzo[c]furazan 1-oxide, $\mathrm{C}_{6} \mathrm{H}_{2} \mathrm{Br}_{2} \mathrm{~N}_{2} \mathrm{O}_{2}$, (II), are normal. Compound (I) occurs in two polymorphic forms. One polymorph contains one molecule in the asymmetric unit, organized into two-dimensional sheets involving intermolecular $\mathrm{N} \cdots \mathrm{Cl}$ and $\mathrm{O} \cdots \mathrm{Cl}$ interactions. The second polymorph has three molecules in the asymmetric unit, organized into two crystallographically different two-dimensional sheets with similar interactions. Compound (II) is isomorphous with the second polymorph of (I). The three two-dimensional sheets in the two polymorphs comprise a set of three two-dimensional polymorphic arrangements.

\section{Comment}

In the structure of 4,7-dibromobenzo[c]furazan 1-oxide, DBR or (II), there are three crystallographically different DBR molecules (Britton, 1992). These pack in two similar but different kinds of layers, both characterized by $\mathrm{Br} \cdots \mathrm{O}$ and $\mathrm{Br} \cdots \mathrm{N}$ intermolecular interactions. The presence of two different kinds of layers was surprising, since either type of layer alone would appear to be a possible motif for a less

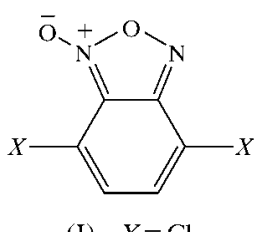

(I) $X=\mathrm{Cl}$

(II) $X=\mathrm{Br}$

complex but satisfactory packing. To explore the question further, we have looked at the crystal structure of the corresponding dichloro compound, DCL or (I). Two polymorphs were found and these are described below. We also report a redetermination of the structure of (II). A search for a second polymorph of (II) was unsuccessful.

Drawings of all the independent molecules in both polymorphs of (I) are shown in Fig. 1, while Fig. 2 shows the corresponding drawings for (II). The bond lengths and angles are all normal, and agree within experimental error, for all four independent molecules of (I) and for all three independent molecules of (II). In addition, the distances and angles between non-halogen atoms agree between the two compounds.

The packing in the two polymorphs of (I), denoted DCL-I and DCL-II, is shown in Figs. 3 and 4; the packing for (II) is the same as that shown in Fig. 4, and the discussion of the packing is the same as that for the second polymorph of (I), hence it is denoted DBR-II. In both polymorphs of (I), there are nearly planar layers. Between the two polymorphs, there are three different kinds of layers: those in polymorph I are denoted Cl-I layers, those in polymorph II involving $A$ molecules are denoted Cl-II $A$ layers, and those in polymorph II involving $B$ and $C$ molecules are denoted $\mathrm{Cl}$-II $B C$ layers.

Although the most important intermolecular interactions would appear to be those between the $\mathrm{Cl}$ atoms of one molecule and the $\mathrm{N}$ or $\mathrm{O}$ atoms of adjacent molecules, we will begin our discussion by focusing on the $\mathrm{C}-\mathrm{H} \cdots \mathrm{O}$ intermolecular interactions that are also present. All three layers can be thought of as beginning with rows of molecules. These are parallel to [110] in polymorph $\mathrm{I}$, with a repeat distance along the row of 7.820 (1) $\AA$. They are parallel to [010] in polymorph II, with each of the $A, B$ and $C$ molecules forming its own row, with a repeat distance of 7.819 (2) $\AA$. The geometric details along these rows are summarized in Table 1. The H. . O distances are similar to those generally found; see Desiraju \& Steiner (1999).
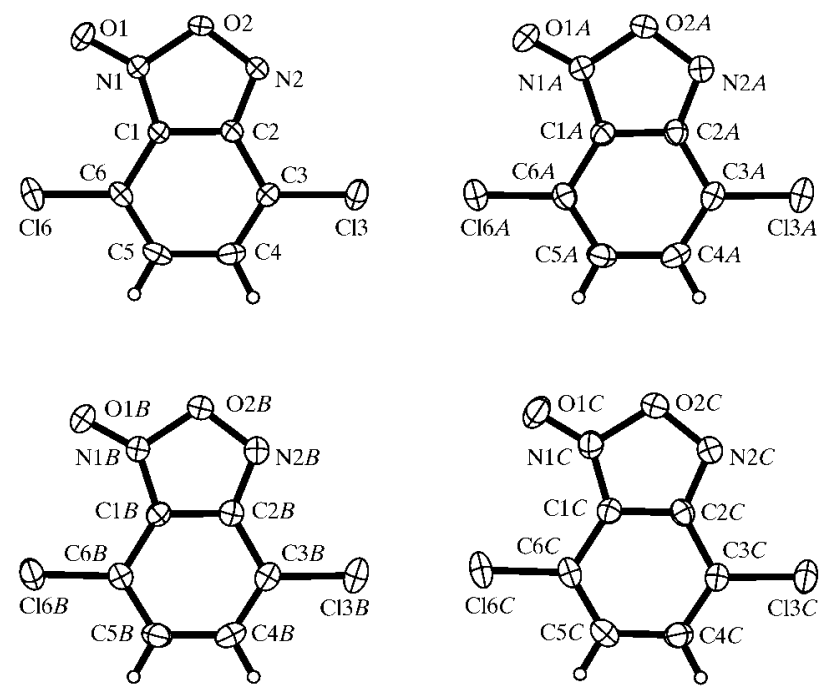

Figure 1

The four independent molecules of (I). Polymorph I is in the upper left corner; the remaining plots are for polymorph II. Displacement ellipsoids are drawn at the $50 \%$ probability level and $\mathrm{H}$ atoms are shown as small spheres of arbitrary radii. 

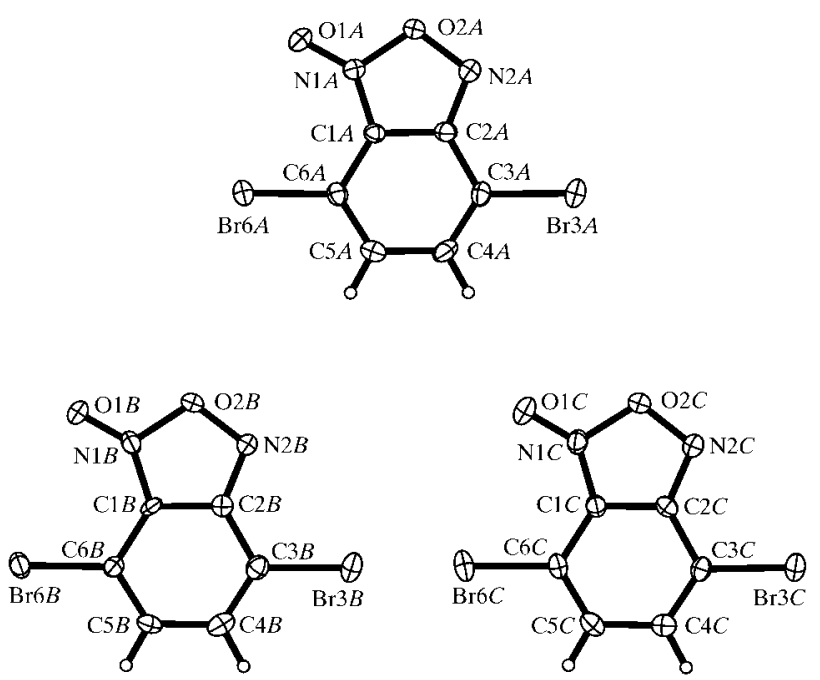

Figure 2

The three independent molecules of (II). Displacement ellipsoids are drawn at the $50 \%$ probability level and $\mathrm{H}$ atoms are shown as small spheres of arbitrary radii.

The rows are combined in three different ways. In polymorph I, they are all parallel to each other and each molecule has contacts with two others on each side. In the two kinds of layers in polymorph II, each molecule has two contacts with the same antiparallel molecule on one side and contacts with two other parallel molecules on the other side. In the Cl-II $A$
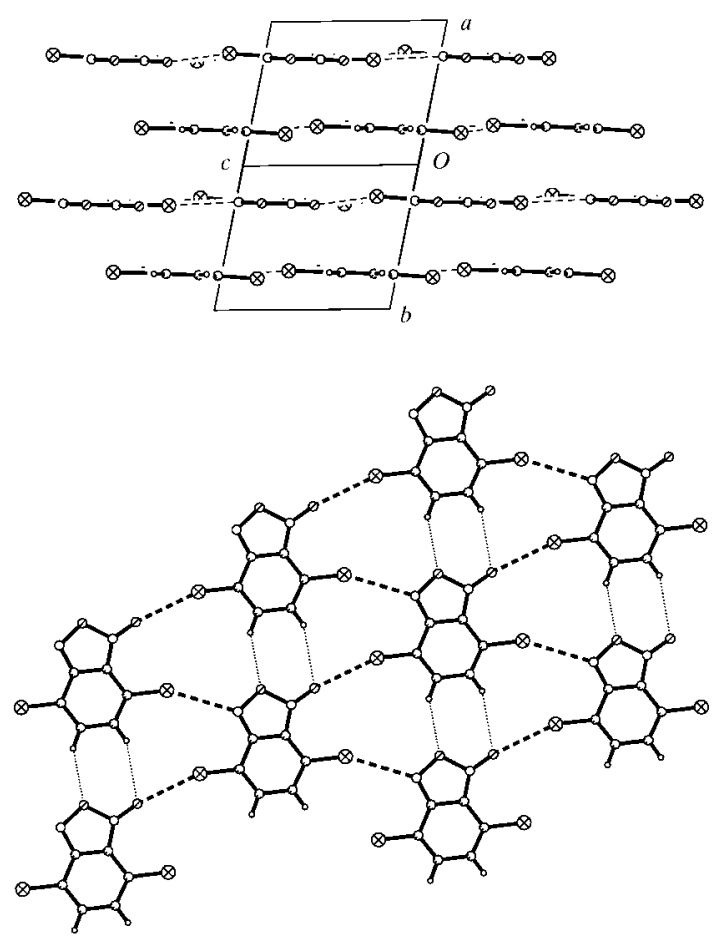

Figure 3

The packing in (I), polymorph I (DCL-I). At the top is a view along the [110] direction. The bottom view is normal to (110). The layer shown is that with four molecules in the top view. Heavy dashed lines indicate $\mathrm{Cl} \cdots \mathrm{O}$ and $\mathrm{Cl} \cdots \mathrm{N}$ interactions, and light dotted lines indicate $\mathrm{C}-\mathrm{H} \cdots \mathrm{O}$ interactions. layers, the two molecules sharing two contacts are related by a center of symmetry, with both contacts being $\mathrm{Cl} \cdots \mathrm{O}$. The contacts between parallel rows are all $\mathrm{Cl} \cdots \mathrm{N}$. In the $\mathrm{Cl}-\mathrm{II} B C$ layers, the two molecules sharing two contacts are one $B$ and one $C$, with one $\mathrm{Cl} \cdots \mathrm{O}$ and one $\mathrm{Cl} \cdots \mathrm{N}$ contact. The contacts between parallel rows alternate between $\mathrm{Cl} \cdots \mathrm{O}$ and $\mathrm{Cl} \cdots \mathrm{N}$. The geometric details for all these contacts are given in Table 2. For an extensive discussion of intermolecular inter-
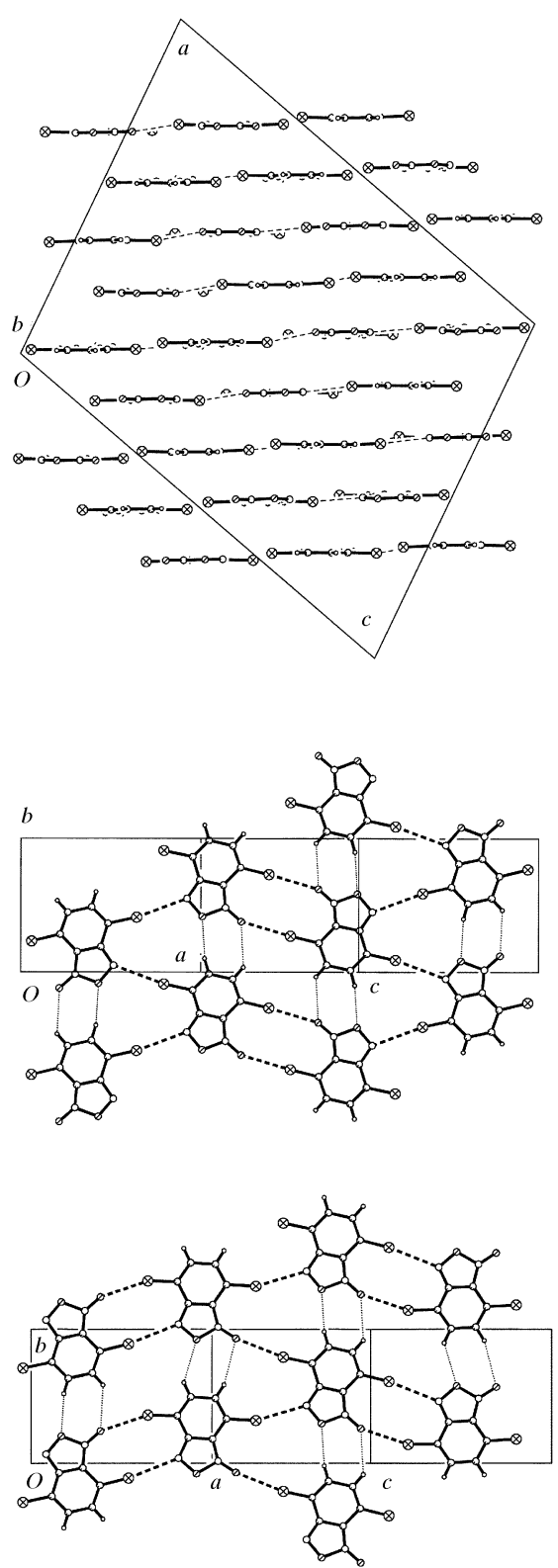

Figure 4

The packing in (I), polymorph II (DCL-II). The upper view is along the $b$ axis. The top part of the lower view is normal to $(10 \overline{1})$, and the layer shown contains the $A$ molecules and passes through the origin in the upper view. The bottom part of the lower view is another view normal to

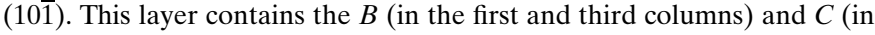
the second and fourth columns) molecules, and crosses the $c$ axis at $c / 3$ in the upper view. Heavy dashed lines indicate $\mathrm{Cl} \cdots \mathrm{O}$ and $\mathrm{Cl} \cdots \mathrm{N}$ interactions, and light dotted lines indicate $\mathrm{C}-\mathrm{H} \cdots \mathrm{O}$ interactions. The packing in (II) is identical. 
actions between halogens and $\mathrm{N}$ or $\mathrm{O}$, see Lommerse et al. (1996).

These two polymorphs involve three two-dimensional polymorphic layers. As was mentioned earlier, it is surprising to have two different kinds of layers in polymorph II. If we consider the molecular volumes for (I), namely $187.9 \AA^{3}$ for polymorph I and $188.7 \AA^{3}$ for polymorph II, it seems likely that polymorph $\mathrm{I}$ is the more stable at low temperature (Dunitz, 1995). This is not inconsistent with the greater difficulty in obtaining crystals of DCL-II. On the other hand, the failure to grow crystals of DBR-I may be a consequence of the greater stability of DBR-II. It would be of interest to prepare 4,7-bromochlorobenzo[c]furazan 1-oxide to see which polymorphs would occur. It would also be of interest to see whether the $\mathrm{Br}$ and $\mathrm{Cl}$ atoms would be ordered or disordered.

\section{Experimental}

Samples of 4,7-dibromobenzo[c]furazan 1-oxide, (II), and 4,7-dichlorobenzo[c]furazan 1-oxide, (I), were prepared as described previously by Mallory et al. (1965). Compound (I) was recrystallized from acetone and the structure determined; the details are given below as DCL-I. Since the purpose of the study was to see whether (I) might be isomorphous with (II), a search was made for other polymorphs. Recrystallization of (I) from acetonitrile, acetone, benzene, methylene chloride, chloroform, carbon tetrachloride, methanol and ethanol all gave polymorph DCL-I. However, crystals of polymorph II were obtained from diethyl ether and propan-2-ol; the latter also gave polymorph I. A crystal from the propan-2-ol crystallization was used for the present structure determination and is reported below as DCL-II. Using the notation suggested by Zorky (1996), polymorph I is in space group $C 2 / c$ with $Z=24\left(1^{3}\right)$, and polymorph II is in space group $P \overline{1}$ with $Z=2$ (1). A similar search was made for polymorphs of (II). However, all of the solvents listed above produced only one polymorph, which is labeled polymorph II to be consistent with (I); no second polymorph of (II) could be found. A crystal grown from acetone was used for the structure determination; the data are given below as DBR-II.

\section{Polymorph DCL-I}

\section{Crystal data}

$\mathrm{C}_{6} \mathrm{H}_{2} \mathrm{Cl}_{2} \mathrm{~N}_{2} \mathrm{O}_{2}$

$M_{r}=205.00$

Triclinic, $P \overline{1}$

$a=7.357$ (2) $\AA$

$b=7.667$ (2) $\AA$

$c=8.190(2) \AA$

$\alpha=92.10(1)^{\circ}$

$\beta=109.81(1)^{\circ}$

$\gamma=117.31(1)^{\circ}$

$V=375.8(2) \AA^{3}$

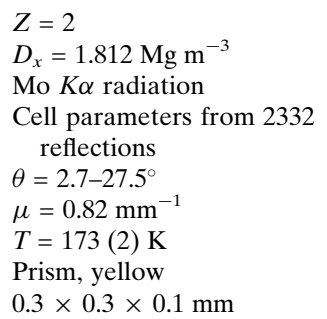

Data collection

Siemens SMART CCD areadetector diffractometer

$\omega$ scans

Absorption correction: multi-scan

[SADABS; Sheldrick (1996) and Blessing (1995)]

$T_{\text {min }}=0.78, T_{\max }=0.92$

4117 measured reflections

1695 independent reflections

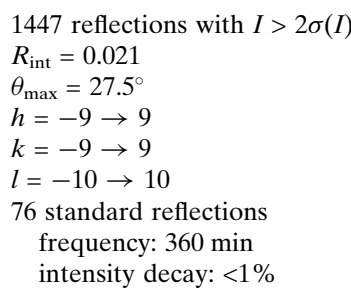

\section{Refinement}

Refinement on $F^{2}$

$R\left[F^{2}>2 \sigma\left(F^{2}\right)\right]=0.034$

$w R\left(F^{2}\right)=0.095$

$S=1.09$

1695 reflections

117 parameters

All $\mathrm{H}$-atom parameters refined

$$
\begin{gathered}
w=1 /\left[\sigma^{2}\left(F_{o}{ }^{2}\right)+(0.0591 P)^{2}\right. \\
+0.0163 P] \\
\text { where } P=\left(F_{o}{ }^{2}+2 F_{c}{ }^{2}\right) / 3 \\
(\Delta / \sigma)_{\max }=0.001 \\
\Delta \rho_{\max }=0.40 \AA^{-3} \\
\Delta \rho_{\min }=-0.34 \mathrm{e}^{-3}
\end{gathered}
$$

\section{Polymorph DCL-II}

\author{
Crystal data \\ $\mathrm{C}_{6} \mathrm{H}_{2} \mathrm{Cl}_{2} \mathrm{~N}_{2} \mathrm{O}_{2}$ \\ $M_{r}=205.00$ \\ Monoclinic, $C 2 / c$ \\ $a=21.828(5) \AA$ \\ $b=7.819$ (2) $\AA$ \\ $c=27.501(7) \AA$ \\ $\beta=105.21(3)^{\circ}$ \\ $V=4529(2) \AA^{3}$ \\ $Z=24$
}

\author{
$D_{x}=1.804 \mathrm{Mg} \mathrm{m}^{-3}$ \\ Mo $K \alpha$ radiation \\ Cell parameters from 1162 \\ reflections \\ $\theta=2.0-27.4^{\circ}$ \\ $\mu=0.81 \mathrm{~mm}^{-1}$ \\ $T=173(2) \mathrm{K}$ \\ Prism, yellow \\ $0.45 \times 0.20 \times 0.20 \mathrm{~mm}$
}

Table 1

Intermolecular $\mathrm{C}-\mathrm{H} \cdots \mathrm{O}-\mathrm{N}$ hydrogen-bond contacts in (I) and (II) $\left(\AA,{ }^{\circ}\right)$.

\begin{tabular}{llllll}
\hline $\mathrm{C}-\mathrm{H} \cdots \mathrm{O}-\mathrm{N}$ & $\mathrm{C}-\mathrm{H}$ & $\mathrm{H} \cdots \mathrm{O}$ & $\mathrm{C} \cdots \mathrm{O}$ & $\mathrm{C}-\mathrm{H} \cdots \mathrm{O}$ & $\mathrm{H} \cdots \mathrm{O}-\mathrm{N}$ \\
\hline $\mathrm{C} 4-\mathrm{H} 4 \cdots \mathrm{O} 2^{\mathrm{i}}-\mathrm{N} 2^{\mathrm{i}}$ & 0.95 & 2.49 & $3.336(2)$ & 149 & 123 \\
$\mathrm{C} 5-\mathrm{H} 5 \cdots \mathrm{O} 1^{\mathrm{i}}-\mathrm{N} 1^{\mathrm{i}}$ & 0.91 & 2.76 & $3.593(2)$ & 154 & 116 \\
$\mathrm{C} 4 A-\mathrm{H} 4 A \cdots \mathrm{O} 2 A^{\mathrm{ii}}-\mathrm{N} 2 A^{\mathrm{ii}}$ & 0.93 & 2.49 & $3.391(2)$ & 165 & 107 \\
$\mathrm{C} 5 A-\mathrm{H} 5 A \cdots \mathrm{O} 1 A^{\mathrm{ii}}-\mathrm{N} 1 A^{\mathrm{ii}}$ & 0.93 & 2.70 & $3.421(2)$ & 135 & 134 \\
$\mathrm{C} 4 B-\mathrm{H} 4 B \cdots \mathrm{O} 2 B^{\mathrm{ii}}-\mathrm{N} 2 B^{\mathrm{ii}}$ & 0.93 & 2.47 & $3.386(2)$ & 167 & 143 \\
$\mathrm{C} 5 B-\mathrm{H} 5 B \cdots \mathrm{O} 1 B^{\mathrm{ii}}-\mathrm{N} 1 B^{\mathrm{ii}}$ & 0.93 & 2.69 & $3.415(2)$ & 135 & 135 \\
$\mathrm{C} 4 C-\mathrm{H} 4 C \cdots \mathrm{O} 2 C^{\mathrm{ii}}-\mathrm{N} 2 C^{\mathrm{ii}}$ & 0.93 & 2.61 & $3.364(2)$ & 138 & 115 \\
$\mathrm{C} 5 C-\mathrm{H} 5 C \cdots \mathrm{O} 1 C^{\mathrm{ii}}-\mathrm{N} 1 C^{\mathrm{ii}}$ & 0.93 & 2.80 & $3.694(2)$ & 162 & 108 \\
$\mathrm{C} 4 A-\mathrm{H} 4 A \cdots \mathrm{O} 2 A^{\mathrm{ii}}-\mathrm{N} 2 A^{\mathrm{ii}}$ & 0.95 & 2.50 & $3.417(5)$ & 164 & 107 \\
$\mathrm{C} 5 A-\mathrm{H} 5 A \cdots \mathrm{O} 1 A^{\mathrm{ii}}-\mathrm{N} 1 A^{\mathrm{ii}}$ & 0.95 & 2.71 & $3.435(5)$ & 134 & 135 \\
$\mathrm{C} 4 B-\mathrm{H} 4 B \cdots \mathrm{O} 2 B^{\mathrm{ii}}-\mathrm{N} 2 B^{\mathrm{ii}}$ & 0.95 & 2.48 & $3.411(4)$ & 168 & 144 \\
$\mathrm{C} 5 B-\mathrm{H} 5 B \cdots \mathrm{O} 1 B^{\mathrm{ii}}-\mathrm{N} 1 B^{\mathrm{ii}}$ & 0.95 & 2.70 & $3.434(4)$ & 134 & 136 \\
$\mathrm{C} 4 C-\mathrm{H} 4 C \cdots \mathrm{O} 2 C^{\mathrm{ii}}-\mathrm{N} 2 C^{\mathrm{ii}}$ & 0.95 & 2.62 & $3.387(5)$ & 138 & 115 \\
$\mathrm{C} 5 C-\mathrm{H} 5 C \cdots \mathrm{O} 1 C^{\mathrm{ii}}-\mathrm{N} 1 C^{\mathrm{ii}}$ & 0.95 & 2.80 & $3.713(4)$ & 161 & 109 \\
\hline
\end{tabular}

Symmetry codes: (i) $1+x, 1+y, z$; (ii) $x, y-1, z$.

Table 2

Distances and angles in the $\mathrm{C}-X \cdots Y-Z$ contacts in (I) and (II) $\left(\AA{ }^{\circ},{ }^{\circ}\right)$.

\begin{tabular}{llll}
\hline $\mathrm{C}-X \cdots Y-Z$ & $\mathrm{C}-X \cdots Y$ & $X \cdots Y$ & $X \cdots Y-Z$ \\
\hline $\mathrm{C} 3-\mathrm{Cl} 3 \cdots \mathrm{O} 1^{\mathrm{i}}-\mathrm{N}^{\mathrm{i}}$ & $157.7(2)$ & $3.010(2)$ & $166.3(2)$ \\
$\mathrm{C} 6-\mathrm{Cl} 6 \cdots 2^{\mathrm{ii}}-\mathrm{O} 2^{\mathrm{ii}}$ & $156.3(2)$ & $3.191(2)$ & $119.3(2)$ \\
$\mathrm{C} 3 A-\mathrm{Cl} 3 A \cdots \mathrm{N} 2 A^{\mathrm{iii}}-\mathrm{O} 2 A^{\mathrm{iii}}$ & $170.8(2)$ & $3.140(2)$ & $109.7(2)$ \\
$\mathrm{C} 6 A-\mathrm{Cl} 6 A \cdots \mathrm{O} 1 A^{\mathrm{iv}}-\mathrm{N} 1 A^{\text {iv }}$ & $168.8(2)$ & $3.045(2)$ & $152.6(2)$ \\
$\mathrm{C} 3 B-\mathrm{Cl} 3 B \cdots \mathrm{O} 1 C-\mathrm{N} 1 C$ & $166.4(2)$ & $2.987(2)$ & $166.8(2)$ \\
$\mathrm{C} 6 B-\mathrm{Cl} 6 B \cdots \mathrm{N} 2 C^{\mathrm{v}}-\mathrm{O} 2 C^{\mathrm{v}}$ & $171.0(2)$ & $3.135(2)$ & $117.4(2)$ \\
$\mathrm{C} 3 C-\mathrm{C} 3 C \cdots \mathrm{O} 1 B^{\mathrm{vi}}-\mathrm{N} 1 B^{\mathrm{vi}}$ & $157.0(2)$ & $2.936(2)$ & $154.7(2)$ \\
$\mathrm{C} 6 C-\mathrm{C} 6 C \cdots \mathrm{N} 2 B^{\mathrm{vii}}-\mathrm{O} 2 B^{\mathrm{vii}}$ & $159.9(2)$ & $3.068(2)$ & $113.1(2)$ \\
$\mathrm{C} 3 A-\mathrm{Br} 3 A \cdots \mathrm{N} 2 A^{\text {iii }}-\mathrm{O} 2 A^{\mathrm{iii}}$ & $172.3(4)$ & $3.131(3)$ & $110.1(3)$ \\
$\mathrm{C} 6 A-\mathrm{Br} 6 A \cdots \mathrm{O} 1 A^{\mathrm{iv}}-\mathrm{N} 1 A^{\text {iv }}$ & $169.1(4)$ & $3.100(3)$ & $152.1(3)$ \\
$\mathrm{C} 3 B-\mathrm{Br} 6 B \cdots \mathrm{O} 1 C-\mathrm{N} 1 C$ & $167.4(4)$ & $2.982(3)$ & $163.4(3)$ \\
$\mathrm{C} 6 B-\mathrm{Br} 6 B \cdots \mathrm{N} 2 C^{\mathrm{v}}-\mathrm{O} 2 C^{\mathrm{v}}$ & $169.8(4)$ & $3.151(3)$ & $117.7(3)$ \\
$\mathrm{C} 3 C-\mathrm{Br} 3 C \cdots \mathrm{O} 1 B^{\mathrm{vi}}-\mathrm{N} 1 B^{\mathrm{vi}}$ & $155.9(4)$ & $2.995(3)$ & $152.2(3)$ \\
$\mathrm{C} 6 C-\mathrm{Br} 6 C \cdots \mathrm{N} 2 B^{\mathrm{vii}}-\mathrm{O} 2 B^{\mathrm{vii}}$ & $159.7(4)$ & $3.093(3)$ & $111.6(3)$ \\
\hline
\end{tabular}

Symmetry codes: (i) $1+x, 1+y .1+z$; (ii) $x, y, z-1$; (iii) $\frac{3}{2}-x, y-\frac{1}{2}, \frac{3}{2}-z$; (iv) $1-x, 1-y, 1-z$; (v) $\frac{1}{2}+x, \frac{1}{2}-y, \frac{1}{2}+z$; (vi) $x-\frac{1}{2}, \frac{1}{2}-y, z-\frac{1}{2}$; (vii) $x, y-1, z$. 


\section{Data collection}

Siemens SMART CCD areadetector diffractometer

$\omega$ scans

Absorption correction: multi-scan

[SADABS; Sheldrick (1996) and Blessing (1995)]

$T_{\text {min }}=0.72, T_{\text {max }}=0.85$

13985 measured reflections

5149 independent reflections

\section{Refinement}

Refinement on $F^{2}$

$R\left[F^{2}>2 \sigma\left(F^{2}\right)\right]=0.034$

$w R\left(F^{2}\right)=0.081$

$S=1.06$

5149 reflections

325 parameters

$\mathrm{H}$-atom parameters constrained

\section{Compound DBR-II}

Crystal data

$\mathrm{C}_{6} \mathrm{H}_{2} \mathrm{Br}_{2} \mathrm{~N}_{2} \mathrm{O}_{2}$

$M_{r}=293.92$

Monoclinic, $C 2 / c$

$a=22.810(6) \AA$

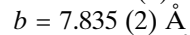

$c=27.859(7) \AA$

$\beta=105.31(2)^{\circ}$

$V=4802(2) \AA^{3}$

$Z=24$

\section{Data collection}

\section{Siemens SMART CCD area-} detector diffractometer

$\omega$ scans

Absorption correction: multi-scan

[SADABS; Sheldrick (1996) and Blessing (1995)]

$T_{\text {min }}=0.10, T_{\text {max }}=0.22$

27206 measured reflections

5513 independent reflections
4301 reflections with $I>2 \sigma(I)$

$R_{\text {int }}=0.020$

$\theta_{\max }=27.5^{\circ}$

$h=-28 \rightarrow 24$

$k=-10 \rightarrow 8$

$l=-33 \rightarrow 35$

227 standard reflections

frequency: $360 \mathrm{~min}$

intensity decay: $<1 \%$

$$
\begin{aligned}
& w=1 /\left[\sigma^{2}\left(F_{o}^{2}\right)+(0.035 P)^{2}\right. \\
& +4.8 P] \\
& \text { where } P=\left(F_{o}{ }^{2}+2 F_{c}{ }^{2}\right) / 3 \\
& (\Delta / \sigma)_{\max }=0.002
\end{aligned}
$$

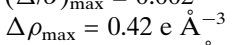

$$
\begin{aligned}
& \Delta \rho_{\min }=-0.29 \mathrm{e}^{-3}
\end{aligned}
$$

Refinement

Refinement on $F^{2}$

$R\left[F^{2}>2 \sigma\left(F^{2}\right)\right]=0.033$

$w R\left(F^{2}\right)=0.058$

$S=1.05$

5513 reflections

325 parameters

$\mathrm{H}$-atom parameters constrained

$$
\begin{aligned}
& w=1 /\left[\sigma^{2}\left(F_{o}{ }^{2}\right)+(0.018 P)^{2}\right. \\
& \quad+6.94 P] \\
& \quad \text { where } P=\left(F_{o}{ }^{2}+2 F_{c}^{2}\right) / 3 \\
& (\Delta / \sigma)_{\max }=0.002 \\
& \Delta \rho_{\max }=0.92 \mathrm{e}^{-3} \\
& \Delta \rho_{\min }=-0.66 \mathrm{e}^{-3}
\end{aligned}
$$

For the triclinic polymorph of (I), H-atom parameters were refined, giving $\mathrm{C}-\mathrm{H}$ distances of 0.91 (2) and 0.95 (2) $\AA$. For the monoclinic polymorph of (I), and also for (II), $\mathrm{H}$ atoms were treated as riding, with $\mathrm{C}-\mathrm{H}$ distances of 0.93 and $0.95 \AA$, respectively.

For both compounds, data collection: SMART (Siemens, 1995); cell refinement: SAINT (Siemens, 1995); data reduction: SAINT; program(s) used to solve structure: SHELXTL (Sheldrick, 1997); program(s) used to refine structure: SHELXTL; molecular graphics: SHELXTL; software used to prepare material for publication: SHELXTL.

Supplementary data for this paper are available from the IUCr electronic archives (Reference: BK1639). Services for accessing these data are described at the back of the journal.

$D_{x}=2.439 \mathrm{Mg} \mathrm{m}^{-3}$

Mo $K \alpha$ radiation

Cell parameters from 2707 reflections

$\theta=2.7-27.2^{\circ}$

$\mu=10.08 \mathrm{~mm}^{-1}$

$T=175$ (2) K

Prism, yellow

$0.25 \times 0.20 \times 0.15 \mathrm{~mm}$

4095 reflections with $I>2 \sigma(I)$

$R_{\text {int }}=0.052$

$\theta_{\max }=27.5^{\circ}$

$h=-29 \rightarrow 29$

$k=-10 \rightarrow 10$

$l=-36 \rightarrow 36$

153 standard reflections frequency: $600 \mathrm{~min}$ intensity decay: $<1 \%$

\section{References}

Blessing, R. H. (1995). Acta Cryst. A51, 33-38.

Britton, D. (1992). Acta Cryst. C48, 1283-1285.

Desiraju, G. R. \& Steiner, T. (1999). The Weak Hydrogen Bond. Oxford University Press.

Dunitz, J. D. (1995). Acta Cryst. B51, 619-631.

Lommerse, J. P. M., Stone, A. J., Taylor, R. \& Allen, F. H. (1996). J. Am. Chem. Soc. 118, 3108-3116.

Mallory, F. B., Manatt, S. L. \& Wood, C. S. (1965). J. Am. Chem. Soc. 87, 5433 5438.

Sheldrick, G. M. (1997). SHELXTL. Version 5.1. Siemens Analytical X-ray Instruments Inc., Madison, Wisconsin, USA.

Sheldrick. G. M. (1996). SADABS. University of Göttingen, Germany.

Siemens (1995). SMART and SAINT. Versions 4.0. Siemens Analytical X-ray Instruments Inc., Madison, Wisconsin, USA.

Zorky, P. M. (1996). J. Mol. Struct. 374, 9-28. 